\title{
Dispersão urbana: degradação e produção da natureza em um contexto de globalização e financeirização
}

\author{
Oséias Teixeira da Silva*
}

\begin{abstract}
Resumo A intensificação do processo de globalização implica em um momento de ruptura no padrão de produção dos espaços urbanos, que resultam em formas de produção do tecido urbano de maneira crescentemente dispersa. Essa nova lógica de produção do espaço urbano está diretamente a estratégias de atuação do capital financeiro. Uma das consequências desse processo de dispersão é tanto uma acentuada degradação da natureza quanto a produção de uma segunda natureza. O presente trabalho visa discutir os paradoxos desse processo de dispersão que ao mesmo tempo se dá utilizando um discurso de reencontro com a natureza ao mesmo tempo que a devasta e a recria como dócil simulacro.
\end{abstract}

Palavras-chave: dispersão urbana, financeirização, degradação da natureza, produção da natureza.

\section{Dispersion urbaine : dégradation et production de la nature dans un contex de mondialisation et de financiarisation}

Resumé Dans les années 1970, I'intensification du processus de mondialisation a entraîné une rupture dans le modèle de production des espaces urbains et un étalement de plus en plus important du tissu urbain. Au fur et à mesure que "I'immobilier se mobilise" de nouvelles formes de production du cadre bâti se répandent dans le monde entier. L'une des conséquences de cette expansion urbaine, sous forme dispersée, réside à la fois dans une dégradation marquée de la nature et la production d'une "seconde nature". Ce chapitre entend montrer comment ces processus recréent une nouvelle nature urbaine, artificielle et pastiche.

Mots-clefs: dispersion urbaine, financiarisation, dégradation de la nature, production de la nature.

\section{Urban dispersion : degradation and production of nature in a context of globalization and finan- cialization}

\begin{abstract}
The intensification of the process of globalization implies a moment of rupture in the pattern of production of urban spaces that result in forms of production of the urban fabric in an increasingly dispersed way. This new logic of urban space production is directly related to the strategies of financial capital. One of the consequences of this process of dispersion is both a marked degradation of nature and a production of a second nature. The present work aims to discuss the paradoxes of this process of dispersion that at the same time occurs using a discourse of reunion with nature at the same time that devastates it and recreates it as docile simulacrum.
\end{abstract}

Keywords: urban dispersion, financialization, degradation of nature, production of nature. 
Não se comanda a natureza senão the obedecendo. (Francis Bacon, Novum Organum, 1620).

A crise do sistema fordista, a intensificação do processo de globalização, os avanços tecnológicos e a financeirização da economia criaram um contexto de expansão do sistema capitalista, extremamente instável e desigual é verdade, mais ainda assim passível de manter a continuidade do processo de acumulação capitalista. Tais transformações estão diretamente relacionadas a mudanças nas mais diferentes esferas da vida social e como não poderia deixar de ser influenciam também de maneira decisiva a forma como se dá a produção do espaço urbano. De forma geral podemos afirmar que o capitalismo hoje, não se limita a produzir um espaço urbano adequado as suas necessidades produtivas (por mais que as contradições da lógica desigual de produção capitalista leve a produção de disfuncionalidades urbanas do ponto de vista do capital, como os congestionamentos, por exemplo) mais ao fato de que a própria produção do espaço se torna uma atividade econômica vital para a acumulação capitalista. Tal diferença é apontada por (Lefebvre, 1999, p 141):

A produção do espaço, em si, não é nova. Os grupos dominantes sempre produziram este ou aquele espaço particular, o das cidades antigas, o dos campos (aí incluídas as paisagens que em seguida parecem naturais). O novo é a produção global e total do espaço social. Essa extensão enorme da atividade produtiva realiza-se em função dos interesses que a inventam, dos que a gerem, dos que nela se beneficiam (largamente). O capitalismo parece esgotar-se. Ele encontrou um novo alento na conquista do espaço. E isso à escala mundial. Esse é o caminho (imprevisto) da socialização das forças produtivas, da própria produção do espaço. É preciso acrescentar que $O$ capitalismo, visando a sua própria sobrevivência, tomou a iniciativa nesse domínio? A estratégia vai muito mais longe que a simples venda, pedaço por pedaço, do espaço. Ela não só faz o espaço entrar na produção da mais valia, ela visa uma reorganização completa da produção subordinada aos centros da informação e decisão.

Como colocado no texto toda sociedade produz o seu espaço de acordo com a maneira como tal sociedade se divide em classes, com a disponibilidade de tecnologias e com as necessidades produtivas de cada sociedade. Assim todo espaço social é, não um reflexo da sociedade mais sim uma forma de tradução espacial do ser social, ou em outras palavras, a maneira como uma sociedade existe concretamente, uma vez que a vida em sociedade implica na necessidade da produção do espaço, de certo espaço de acordo com as demandas dessa sociedade. Se toda a sociedade produz espaço, esta produção tem que se dar de uma forma que viabilize a reprodução dessa sociedade, estando, portanto, a produção do espaço diretamente ligada à reprodução social. Assim todo grupo social dominante, sempre necessitou, para viabilizar a sua

* Oséias Teixeira da Silva é Geógrafo, Professor do Programa de Pós-graduação em Engenharia Ambiental, Instituto Federal Fluminense - IFF, ORCID <https:// orcid.org/0000-0003-32930336>. dominação e sua manutenção enquanto classe dominante da produção de um espaço que atendesse esses interesses e que em alguns casos viabilize-se também a produção e/ou comercialização de produtos. Assim o espaço urbano sempre foi um suporte a manutenção do poder político e em alguns casos também da produção manufatureira bem como de atividades comerciais. 
Porém na atualidade o espaço urbano não é produzido apenas como suporte ao controle político ou das atividades produtivas e comerciais. Tais funções permanecem, porém a novidade é que hoje o espaço é predominantemente produzido já diretamente como um produto, ou seja, o processo de acumulação de capital ocorre não apenas tendo o espaço como suporte mais fundamentalmente pela própria produção do espaço enquanto atividade produtiva geradora de mais-valia. Não se trata simplesmente da venda, pedaço por pedaço, do espaço urbano, algo bastante antigo no capitalismo, mas da produção global e total do espaço. Isto significa que o espaço tende a ser produzido totalmente como mercadoria, ao passo que tal tendência se difunde globalmente, tendo como o resultado o fato das diferentes cidades do mundo serem cada vez mais parecidas.

Tal processo de produção do espaço como mercadoria, tende a se tornar dominante a partir da década de 1970, em um contexto de crise econômica, intensificação da globalização e drástica alteração dos padrões produtivos. Nesse contexto acentuase uma tendência a dispersão dos tecidos urbanos de cidades das mais diferentes dimensões sendo esse processo captado fortemente pela bibliografia especializada que produz toda uma gama de conceitos buscando compreender essa nova realidade. Isto significa que o espaço socialmente produzido, principalmente o espaço urbano, mais que um mero suporte a realização das atividades produtivas, é em si um dos principais produtos relacionados à acumulação de capital. Assim ao invés de somente produzir mercadorias no espaço, há também à produção do espaço enquanto mercadoria. Espaço produzido globalmente, seguindo as mesmas tendências de desenvolvimento e, portanto cada vez mais parecido ao passo que intensamente fragmentado tanto jurídica quanto socialmente.

A conversão do espaço urbano em uma das principais atividades produtoras de mais valia está diretamente ligada a financeirização da produção do espaço capitalista, sob a égide do capital incorporador. No Brasil (Oliveira; Shimbo, 2011, p 3), mostra, por exemplo, que no bojo da expansão do Programa Minha Casa Minha Vida, há um movimento de expansão do capital de incorporação com o surgimento de novas empresas e a abertura de capital de empresas existentes, que recebem grande volume de investimentos financeiros. Boa parte desses investidores se refere a fundos de investimento que passam a controlar ou a criar novas empresas para atuar no setor imobiliário. Assim o crescimento do setor está diretamente ligado a financeirização das empresas do setor que passam a ter uma escala de atuação nacional, ao passo que muitas vezes são controladas por grandes investidores internacionais.

No bojo da intensificação da produção do espaço urbano como uma estratégia de reprodução do capital financeirizado, tem se a intensificação da dispersão do processo de urbanização. Podemos afirmar que a dispersão é uma consequência direta do fato de que a produção do urbano ser hoje um elemento central para a reprodução do capital. No próximo tópico buscaremos desenvolver um argumento que explore a relação entre a produção do espaço urbano enquanto elemento central para a reprodução do capital via produção de mais valia e a dispersão urbana. No tópico seguinte buscaremos explorar a relação entre essa produção de um urbano disperso e a degradação da natureza bem como a constante recriação da natureza enquanto um dócil simulacro. 


\section{A produção do espaço como produto do capital e a dispersão urbana}

Os vínculos entre o capital financeiro e imobiliário não são novos na sociedade capitalista, o que facilmente se constata pelo fato de que bolhas especulativas nos mercados financeiros normalmente se formam ao mesmo tempo em que se formam bolhas no mercado imobiliário, especialmente em contextos de alta liquidez e baixas taxas de juros, como ocorreu durante a crise de 2008 (Harvey, 2011). Tais vínculos tem se intensificado nas últimas décadas, especialmente a partir da criação de novos instrumentos financeiros, entre eles a securitização e os fundos imobiliários. Tais instrumentos permitiram que a liquidez gerada no capital financeiro pudesse fluir com facilidade para os investimentos na produção imobiliária. Os movimentos de desregulamentação financeira, estimuladas em todo o mundo pelo Consenso de Washington, facilitaram a criação desses instrumentos financeiros nos mais diversos países do mundo. (Fix, 2011) aponta para o fato de que todos os instrumentos financeiros diretamente ligados à crise dos subprimes nos EUA, já estavam presentes no Brasil embora com uma importância menor do que em relação à produção imobiliária americana.

Não buscaremos aprofundar nesse trabalho, as relações entre o capital financeiro e imobiliário, uma vez que tal objetivo nos afastaria da discussão sobre dispersão urbana e degradação/produção da natureza. Ao invés disso buscaremos analisar a relação entre a atuação do capital, cada vez mais financeirizado, que é investido no setor imobiliário, e a dispersão urbana que como tendência da urbanização está diretamente relacionada à produção imobiliária realizada como estratégia de reprodução do capital.

A dispersão urbana está diretamente ligada à estratégia de reprodução do capital financeirizado investido na produção imobiliária. A produção imobiliária via capital de incorporação financeirizado, se dá na escala do empreendimento, que geralmente tem uma grande dimensão embora o empreendimento seja uma unidade de produção individualizada. Anteriormente a produção se dava na dimensão de uma área, que poderia ser um bairro ou um setor, produção para a qual convergiam inúmeros agentes com interesses diferenciados e às vezes até contraditórios. A produção de uma área comercial, por exemplo, envolve os interesses e ações de lojistas, empresas de ônibus, construtoras, prestadores de serviços, ambulantes, etc. Se trata, portanto de uma forma de produção do espaço que se configura pela ação convergente de diferentes agentes, capitalistas ou não, sendo o espaço produzido o resultado conjunto da ação de todos esses agentes, sendo que cada um deles é incapaz de prever ou controlar individualmente as tendências de evolução do espaço produzido.

Tal forma de produção permanece no urbano atual, porém a forma de produção dominante, não necessariamente com maior abrangência espacial, é a produção imobiliária que se dá a partir do capital de incorporação financeirizado, que se dá na escala do empreendimento, sendo este diretamente controlado e regulado pelo capital. Assim temos uma forma de produção do espaço urbano bastante distante do que tínhamos anteriormente. Nesse primeiro momento "(o espaço) era constituído por áreas homogêneas do ponto de vista social, ou funcionalmente especializadas, as quais estavam ligadas por relações complementaridade e interdependência, com frequência numa organização de tipo hierárquico" (Salgueiro, 1998, p 40). 
As áreas homogêneas são resultado de uma ação convergente, entre diversos agentes com interesses semelhantes ou mesmo contraditórios, sendo o espaço produzido o resultado desse conjunto de ações individualizadas no tempo e no espaço. A partir dessa forma de produção vão se configurando áreas homogêneas, resultado direto da convergência de ações individuais. Como essas áreas não são independentes, elas se articulam a partir de diferentes tipos de fluxos, que se organizam comumente de forma hierárquica. Só para retomar um exemplo anteriormente citado, o da área central, a concentração de atividades comerciais em um centro estimula a intensificação de novos estabelecimentos comerciais nesse centro. As relações entre centros normalmente se dá de forma hierárquica tendo alguns centros maior importância que outros. Por outro lado um bairro de classe média alta se constitui a partir de atração continua de novos moradores de classe média alta para esse bairro.

Como nenhum agente controla individualmente a produção do espaço, da mesma forma, nenhum agente controla a localização da área produzida. Assim nenhum indivíduo pode escolher aonde será produzido um bairro de classe média, pode apenas, caso tenha condição financeira para isso, escolher morar nesse local. Totalmente distinta é a situação que temos na atualidade que (Salgueiro, 1998, p 41) denomina cidade fragmentada. Segundo a autora: "a principal característica que importa sublinhar na cidade fragmentada é a existência de enclaves, o caráter pontual de implantações que introduzem uma diferença brusca em relação ao tecido que o cerca, seja um centro comercial numa periferia rural ou um condomínio de luxo no meio de um bairro popular". A produção de enclaves, característica fundamental do processo de urbanização marcado pela fragmentação representa uma ruptura em relação à forma de produção do espaço anteriormente descrita.

O enclave é um empreendimento imobiliário produzido por uma empresa ou um conjunto de empresas capitalistas, normalmente empresas incorporadoras, tendo um estreito vínculo com o capital financeiro, tanto porque as empresas têm capital aberto ou são controladas por fundos ou outras instituições financeiras, tanto pelo fato de que o financiamento seja da produção do imóvel seja da comercialização das unidades é feita com o auxílio do crédito bancário bem como de novos instrumentos financeiros como a securitização. Como se trata de um empreendimento privado os agentes capitalistas responsáveis pela produção tem controle direto tanto sobre a produção quanto sobre o funcionamento dos enclaves. (Caldeira, 2000, p 12) aponta outros aspectos do funcionamento dos enclaves:

Os enclaves fortificados são espaços privatizados fechados e monitorados destinados à residência, lazer, trabalho e consumo. Podem ser shopping centers, conjuntos comerciais e empresariais, ou condomínios residenciais. Eles atraem aqueles que temem a heterogeneidade social dos bairros urbanos mais antigos e preferem abandoná-los para os pobres, os marginais, os 'sem teto'. Por serem espaços fechados cujo acesso é controlado privadamente, ainda que tenham um uso coletivo e semi-público, eles transformam profundamente o caráter do espaço público.

O termo enclave se justifica porque cada empreendimento pode representar uma relativa ruptura em relação ao entorno imediato. Isto se dá porque cada enclave busca reproduzir dentro de seu microcosmo uma versão idealizada e completa do urbano. Além disso, a partir dos enclaves se configura uma vivência em rede em 
que a socialização se dá a partir do uso de diferentes enclaves (escola particular, clube, shopping, etc.) sem necessidade de viver o entorno. Um shopping voltado ao consumo de população de classe média, pode se localizar em uma estrada, num entorno formado por loteamentos populares. O termo fortificado advém do fato de que os enclaves têm uma preocupação quase obsessiva com segurança e exclusividade social. Em relação à produção um aspecto essencial dos enclaves é o fato de que a sua localização, produção e funcionamento é gerido por empresas capitalistas visando à acumulação de capital. Assim o enclave, por ser um empreendimento privado e por não ter necessidade de continuidade em relação ao seu entorno, pode se localizar em diferentes lugares, mesmo fora do tecido urbano consolidado.

Justamente por isso à medida que a produção imobiliária via capital imobiliário se torna cada vez mais financeirizada se dá predominantemente a partir da produção de enclaves, o resultado conjunto dessa produção é o incremento da dispersão urbana. Uma vez que a produção imobiliária é feita predominantemente a partir da criação de enclaves, e como cada enclave pode a princípio se localizar em qualquer área do tecido urbano e mesmo nas suas imediações, existe uma tendência ao incremento da dispersão urbana, justamente porque a produção imobiliária depende de decisões de capitalistas individuais que se remetem ao preço e disponibilidade de terrenos. Portanto, como cada empresa pode escolher localizar seu empreendimento em uma área distinta criam se múltiplos focos de valorização o que permite a intensificação da dispersão urbana.

A ideia de dispersão urbana pode ser relacionada ao conceito de fragmentação sócio espacial. A dispersão urbana pode ser vista, por outro lado, como a expressão espacial da fragmentação sócio espacial. O processo de fragmentação indica uma situação em que as classes sociais passam a ter uma vivência espacialmente fragmentada, em rede, ao passo que as relações construídas com o entorno se enfraquecem. A dispersão urbana é, portanto, a forma de processo de produção do espaço que condiciona a ocorrência da fragmentação sócio espacial, em outras palavras à medida que a produção do espaço se dá predominantemente a partir de enclaves, fisicamente distantes entre si, as formas de sociabilidade acabam sendo construídas a partir do uso desses enclaves. Isso ocorre especialmente em casos de estratos de renda média e alta, que passam a conviver em inúmeros enclaves, como escolas privadas, shopping centers e clubes, fisicamente distantes entre si, enquanto desconhecem completamente o entorno de suas residências.

A dispersão está também diretamente relacionada com a ideia de concentração, (Lencioni, 2008, p 9):

Essa combinação de dispersão e concentração é que configura o espaço da metrópole contemporânea. A metrópole coesa, como "grande cidade", é a forma clássica da metrópole. O seu espraiamento por um extenso território e seus limites imprecisos pode levar a entender que o que é disperso não é o aglomerado, mas o novo patamar da urbanização. Trata-se apenas de uma aparência, pois o que é disperso é a forma que assume a aglomeração. Seja qual for à configuração metropolitana, quer seja um espaço mais denso ou mais disperso, esse espaço é condição, processo e produto associado à urbanização, que tem na ideia de aglomeração um dos elementos centrais de sua definição. Portanto, o que é disperso é sua forma. 
Portanto a urbanização dispersa se caracteriza por combinar a dispersão e aquilo que é aparentemente o seu contrário: concentração tendo como resultado uma aglomeração de outro patamar. A aglomeração é dispersa em sua forma, uma vez que é composta por diversas áreas urbanizadas descontínuas, cada uma delas constituída por diversos enclaves, assim como outras formas de urbanização como favelas, loteamentos populares e conjuntos habitacionais. Assim podemos afirmar que a dispersão urbana se trata de uma modalidade de expansão urbana, mas uma modalidade bastante específica, que se dá sempre repondo a condição da aglomeração urbana como dispersa, ou seja, uma expansão urbana que cria continuamente novas áreas dispersas, sem que necessariamente essas novas áreas se tornem mais densas e compactas com o passar do tempo. No entanto a aglomeração urbana como um todo, apesar de continuamente sendo produzida e reproduzida como dispersa continua sendo uma concentração, embora tendo uma dimensão escalar muito maior. Assim temos como tendência uma urbanização que dispersa a forma tecido urbano somente para reafirmar a unidade do urbano do ponto de vista dos fluxos, em outra escala: uma escala regional. Sobre esse aspecto (Soja, 2013, p 15), afirma o seguinte:

À frente desses desdobramentos, na minha perspectiva, esteve a identificação de um processo de urbanização regional policêntrica, acompanhado por um relativo declínio do que pode ser descrito como um modelo distintamente metropolitano de crescimento e de mudança urbanos. A literatura urbana dominante ainda não reconheceu este modelo regional de urbanização de forma explícita, mas há sinais de que a transformação da urbanização metropolitana para a regional e o uso de termos associados tais como cidades-região e cidades regionais crescerão em importância para a análise geográfica urbana ao longo da próxima década.

Assim teríamos principalmente em áreas metropolitanas, mas não somente nelas, a configuração de uma urbanização regional policêntrica. Regional porque, justamente pelo caráter disperso, configura uma área urbana de dimensão regional. Portanto trata-se de uma região que funciona como uma cidade, fato que se percebe, por exemplo, no intenso deslocamento dos mais diversos tipos de fluxos entre os diferentes locais dessa região. Policêntrica porque essa área urbana regional possui diversos polos de concentração de atividades econômicas, polos esses diferenciados e não necessariamente se relacionando de forma hierárquica. Nesse contexto um modelo diretamente metropolitano de desenvolvimento urbano se espraia pelo território, estando presente mesmo em áreas não efetivamente metropolitanas. Assim signos e atividades anteriormente encontradas somente na metrópole passam a estarem presentes em praticamente todo espaço urbano.

Para compreender o papel da dispersão no contexto da urbanização atual é preciso, no nosso ponto de vista, discutir a noção de dominância. Tal noção é importante para evitarmos posições teóricas extremas: quais sejam a de compreender a dispersão urbana como algo absolutamente novo ou por outro lado concluir que não há nada de novo na dispersão urbana que se desenvolve na atualidade. Sobre a noção de dominância, pode ser um bom ponto de partida analisar a exposição de (Marx, 2003, p 266) sobre o papel da renda da terra no capitalismo:

Parece muito natural, por exemplo, que se comece (a análise) pela renda territorial, a propriedade rural, porque se encontra ligada à terra, fonte de toda produção e vida, 
e à agricultura, primeira forma de produção em todas as sociedades, por pouco solidificadas que se achem. E, contudo, nada mais falso do que isso. Em todas as formas de sociedade se encontra uma produção determinada, superior a todas as demais, e cuja situação aponta sua posição e sua influência sobre as outras. E uma iluminação universal em que atuam todas as cores, e às quais modifica em sua particularidade. É um éter especial, que determina o peso específico de todas as coisas às quais põe em relevo. (Na sociedade capitalista) A agricultura transforma-se mais e mais em simples ramo da indústria e é dominada completamente pelo capital. A mesma coisa ocorre com a renda territorial. Em todas as formas em que domina a propriedade rural, a relação com a natureza é preponderante. Naquelas em que reina o capital, o que prevalece é o elemento social produzido historicamente. Não se compreende a renda territorial sem o capital; entretanto, compreende-se o capital sem a renda rural. O capital é a potência econômica da sociedade burguesa, que domina tudo.

O que o autor aponta é que a renda da terra é a categoria econômica mais antiga do ponto de vista histórico, sendo ainda uma categoria diretamente ligada à produção agrícola que é a princípio fonte de toda riqueza, sendo a atividade que viabiliza a reprodução biológica das sociedades humanas. Além disso, e este é um ponto não presente no texto, mas que podemos acrescentar a discussão podemos apontar que a renda territorial, pelo menos no momento em que Marx escreveu esse texto, era a forma predominante de relação econômica entre seres humanos, uma vez que a maior parte da população se dedicava naquele momento a atividades agrícolas. No entanto, o autor afirma que é absolutamente falso começar o estudo da economia capitalista a partir da renda da terra, isto porque em cada modo de produção temos uma relação econômica dominante que subordina todas as outras. Em muitas sociedades pré-capitalistas essa relação econômica dominante era fundada na propriedade territorial e na renda da terra, porém no capitalismo a relação econômica dominante está fundada no capital. O capital, portanto, é o elemento dominante, que subordina todas as demais relações econômicas e não econômicas.

Isto significa que a compreensão da sociedade capitalista precisa partir da análise do capital e não da renda da terra, uma vez que na sociedade capitalista, o capital explica a renda da terra, uma vez que a agricultura se subordina as demandas do capital. Portanto, mesmo sem ser a relação econômica predominante em termos quantitativos, ou seja, aquela que envolve a maioria da força de trabalho, o capital é a relação dominante no sentido de que é a potência que domina tudo e é também a chave para a compreensão de todas as relações econômicas subordinadas.

Em analogia ao exposto sobre o capital, podemos afirmar que a dispersão urbana hoje é uma característica central do processo de urbanização atual, sendo um elemento que domina formas anteriores de produção do espaço, que permanecem existindo e ao mesmo tempo se coloca como uma chave para a compreensão da realidade urbana contemporânea, mesmo que a dispersão não represente, em termos qualitativos, a forma predominante de produção do espaço urbano na atualidade. Assim embora a dispersão tenha provavelmente sempre existido como elemento do processo de urbanização, ele teria se tornado atualmente, no bojo do processo de financeirização da produção imobiliária, em elemento dominante desse processo. 
Obviamente a dispersão urbana não desenvolve da mesma forma e com o mesmo ritmo nas diferentes lugares do mundo. No entanto percebe-se uma tendência a dispersão crescente dos espaços urbanos que vão tornando as cidades cada vez mais parecidas ao redor, termos como angelinização são utilizados para se referenciar ao fato das cidades serem cada vez mais dispersas e parecidas entre si. Em relação a Europa Dematteis (1996) aponta para o fato de as cidades anglo-saxônicas e mediterrâneas, de formações históricas tão diferentes tem se tornado, a partir do processo de dispersão urbana, muito semelhantes. Segundo o autor:

Con la periurbanización y la «ciudad difusa» los modelos de la suburbanización de tipo latino-mediterráneo y de tipo anglosajón, que durante mucho tiempo han seguido caminos diferentes, tienden ahora a converger en un modelo único común a toda Europa de «ciudad sin centro» de estructura reticular, cuyos «nodos» (sistemas urbanos singulares) conservan y acentúan su identidad a través de procesos innovadores de competición y cooperación. Las nuevas periferias parecen así destinadas a convertirse en la verdadera metrópoli, hecho que se refleja también en una mutación de las imágenes de las periferias mismas, de una negativa propia de la ciudad fordista a otra positiva característica de la ciudad difusa posfordista.

Portanto, dois padrões distintos de urbanização europeia tendem a convergir em modelo único de cidade dispersa e policêntrica, em que se configuram novo tipo de periferia, com forte presença de serviços e atividades produtivas diversas. No Brasil esse processo de dispersão também parte de um modelo de urbanização distinto, no qual temos um centro concentrador de infraestrutura e uma periferia carente de infraestrutura e oportunidades sociais. A dispersão urbana nas cidades brasileiras se dá também pela construção de um novo tipo de periferia que deixa de ser um espaço identificado somente pela presença da pobreza, passando a abrigar diferentes empreendimentos residenciais, comerciais e mesmo industriais. Essa urbanização dispersa está diretamente ligada a uma transformação na forma da relação entre a urbanização e a natureza. Tal relação se caracterizaria por um evidente paradoxo sendo que teríamos tanto a devastação da natureza quanto a produção de uma natureza, um simulacro de natureza, porém dócil e domesticada. No próximo tópico, a partir da discussão aqui realizada sobre a dispersão buscaremos analisar esse aparente paradoxo e o seu significado para o processo de produção do espaço.

\section{Dispersão urbana: degradação da natureza e produção da natureza como simulacro}

Uma das consequências mais marcantes da dispersão urbana é a transformação da relação do urbano com a natureza. De forma geral, podemos afirmar que o urbano sempre foi produzido em torno de uma relação tensa e contraditória com a natureza. Por um lado a produção do urbano e da cidade, sempre significou, em qualquer sociedade, um afastamento e mesmo uma negação da natureza. Como grande obra humana, a vida na cidade significa um afastamento da natureza uma vez que, por exemplo, todo morador da cidade não produz produtos agrícolas tendo que se abastecer no mercado. Por outro lado na cidade sempre se buscou uma reaproximação com a natureza. Assim o urbano sempre foi produzido a partir da tensão dialética entre o afastamento/reaproximação da natureza. Dois expoentes da arquitetura moderna exemplificam essa tensão constante na relação entre o urbano e natureza: por um 
Figura 1: Esquema de zona metropolitana e periferia expandida. Fonte: (Aguillar, 2002, p 4). lado Ebenezer Howard, com o conceito de cidade-jardim propunha uma reaproximação da cidade com a natureza, criando uma cidade dispersa, pouco densa, e com forte presença de áreas verdes; por outro lado Le Corbusier propunha um urbano monumental e artificializado, que indicava a supremacia do homem e da cidade sobre a natureza. A tendência de crescente dispersão dos tecidos urbanos intensifica essa tensão/contradição na relação cidade/natureza de uma forma bem específica. Por um lado a dispersão urbana implica em uma intensa devastação da natureza, como ocorre, por exemplo, quando há a conversão do solo ocupado com vegetação nativa em áreas urbanizadas. Por outro lado e concomitantemente, como uma estratégia de venda dos enclaves, tem se a mercantilização da busca por uma reaproximação com a natureza e produção de uma natureza-artificial como elemento de valorização dos empreendimentos. Sendo que essa natureza não é mais a natureza-natural hostil e misteriosa, mas uma segunda natureza, artificial, dócil e agradável, um perfeito simulacro.

A dispersão urbana implica em uma ampla devastação e alteração de formas naturais ou próximas a natureza. Uma vez que com a dispersão urbana tem se a produção de áreas urbanizadas e enclaves em áreas afastadas do tecido urbano consolidado, obviamente tal dispersão implica na conversão de espaços com outros usos em espaços urbanizados. Esses outros usos podem se referir a atividades agropecuárias bem como a áreas de vegetação nativa. No primeiro caso embora se trate da transformação de uma forma de área antropizada em outra, a urbanização implica em diversas transformações referentes à dinâmica climática, as formas de escoamento da água, etc. Portanto trata-se de uma metamorfose em que se antes temos uma área ocupada por uma atividade humana, mas que em boa parte depende dos ciclos naturais, no segundo caso temos uma área totalmente artificializada no qual os ciclos naturais pouca importância tem para o funcionamento das atividades econômicas. No segundo caso temos uma alteração ainda mais brusca, que envolve a substituição de um ecossistema natural por um ambiente urbanizado e artificializado. Nesse sentido a dispersão implica num processo de intensificação do consumo e conversão do solo para atividades urbanas. Sem apontar as consequências ambientais desse fato, (Aguillar, 2002, p 4) demonstra essa situação ao apontar para um modelo de crescimento urbano disperso no esquema abaixo.

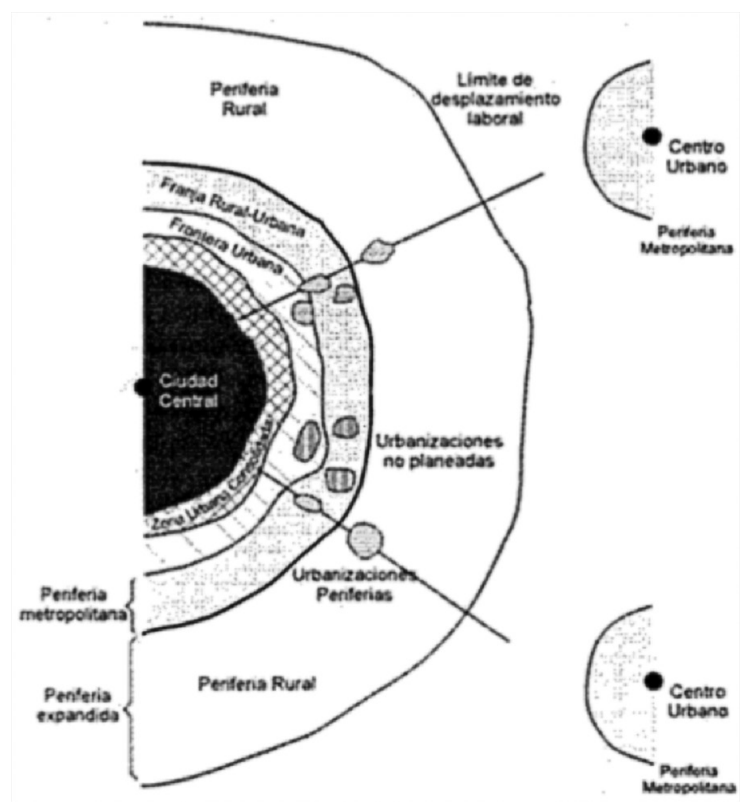


Embora o modelo apresentado pelo autor se refira a realidade metropolitana, a dispersão é uma tendência de desenvolvimento que embora se desenvolva com mais intensidade nas metrópoles ocorre, como tendência, em centros urbanos de diferentes tamanhos. Um dos aspectos interessantes do modelo apontado pelo autor é que com a dispersão urbana as áreas rurais passam a estar cada vez mais envolvidas na dinâmica urbana. O diferencial de preço entre o solo urbano e o rural e a ubiquidade dos empreendimentos na forma de enclaves, permite que a instalação destes em áreas rurais seja uma possibilidade extremamente viável. Isto se dá entre outros motivos, pelo fato do enclave reproduzir em si, características do urbano que antes eram encontradas apenas nos centros tradicionais e também pelo fato de que a localização dos enclaves se insere em uma trama regional/urbana de deslocamentos que não envolvem necessariamente a necessidade da contiguidade. Nesse sentido o elemento central para compreender a possibilidade de conversão é rentabilidade das atividades rurais desenvolvidas. Quanto menor essa rentabilidade maior a possibilidade da conversão, assim áreas rurais com solo deteriorado e criação de gado extensiva, ou de pequena produção de alimentos, comuns em franjas urbanas no Brasil, se tornam extremamente viáveis para a localização desse tipo de empreendimento.

O que apontamos com isso é que a dispersão urbana aponta para reversão completa na relação tradicional entre cidade e campo. Pois a cidade sempre dependeu da produtividade do campo para se expandir, sendo a produtividade agrícola um limite de difícil transposição nas sociedades urbanas pré-capitalistas. Assim a expansão da cidade era regulada pelo campo. Com todo o avanço tecnológico associado à acumulação capitalista, temos com a dispersão urbana uma situação em que avanço dos tecidos urbanos, da cidade, regula a expansão ou contração das áreas rurais. Assim é como se todas as áreas rurais, principalmente se não tiverem uma altíssima rentabilidade, se transformassem em reserva para expansão futura do tecido urbano. Uma das consequências diretas desse fato é a intensa degradação da natureza causado pela produção dos enclaves, que tem como um de seus elementos centrais de atração de compradores, justamente a proximidade dos empreendimentos com a natureza. (Blinickov, et all, 2006, p 65) aponta para essa contradição no trecho a seguir:

Ironically, the new developments advertise themselves as "clean and green" with massive investments in unnatural landscaping (seeded lawns, exotic shrubs, river and lake shore "improvements"). This investment highlights the well-known paradox of development in which people move out of town to live near nature, while destroying the wild nature they come to enjoy.

O paradoxo descrito no trecho acima aponta para o fato de os empreendimentos imobiliários produzidos sob a forma de enclaves, sejam eles condomínios fechados, shoppings, centros empresariais, resorts, etc. geralmente se autoproclamam como empreendimentos limpos e verdes. Assim tais empreendimentos assumem o discurso de desenvolvimento sustentável, vendendo a ideia que são empreendimentos com baixo impacto ambiental. A ideia de que são empreendimentos verdes é viabilizado pela construção de áreas não naturais mais que simulam espaços naturais, o que envolve muitas vezes plantio de vegetação exótica, muito mais em função da estética do que de sua função ecológica. Ao mesmo tempo tais empreendimentos, são produzidos a partir da devastação de espaços naturais e rurais, advindo daí o paradoxo de que as pessoas se deslocam para as periferias em busca de uma vida mais próxima da 
natureza, enquanto a produção imobiliária que viabiliza esse desejo se dá a partir da destruição da natureza-natural e sua substituição por uma segunda natureza-artificial e produzida como um simulacro, como uma versão dócil e romantizada da naturezanatural. Assim passamos de um paradoxo a outro: a busca pela proximidade com a natureza que motiva a destruição dessa mesma natureza e a produção de uma natureza-artificial que simula a natureza-natural.

Antes de prosseguirmos precisamos aprofundar a oposição anteriormente esboçada entre natureza-natural e natureza-artificial. A natureza-natural se refere a espaços ocupados por ecossistemas naturais ou mesmo agrossistemas, espaços esses que por mais que sejam impactados ou influenciados pelas atividades humanas, tem seu funcionamento diretamente ligado aos ciclos e tempos da natureza. Trata-se de natureza não apenas porque se originou de processos naturais, mas também porque seu funcionamento é regulado por processos naturais, mesmo que influenciados por atividades humanas. Assim uma floresta, por mais que seja regulamentada, controlada e utilizada pelas sociedades humanas, tem sua dinâmica diretamente ligada aos ritmos da natureza. Por outro lado à natureza-artificial diz respeito a espaços que embora simulem ser naturais, são produzidos e controlados pela ação humana. Assim tratase de uma natureza-artificial não apenas porque foi produzida pelo homem mais porque seu funcionamento também é regulado pelo homem. Um bosque artificial, plantado com árvores exóticas, apenas pelo efeito estético que produzem é artificial não apenas por ter sido produzido pelo homem mais porque inclusive seu crescimento é por ele regulado. A partir disso podemos compreender o segundo paradoxo, que diz respeito à busca pela natureza-natural que implica na devastação dessa natureza e na produção de uma segunda natureza, uma natureza-artificial, produzida como simulacro que lembra a natureza-natural, mas que não o é. (Lefebvre, 1999, p 34) discute essa relação entre urbanização e natureza no trecho a seguir:

Teoricamente, a natureza distancia-se, mas os signos da natureza e do natural se multiplicam, substituindo e suplantando a 'natureza real'. Tais signos são produzidos e vendidos em massa. Uma árvore, uma flor, um ramo, um perfume, uma palavra tornam se signos da ausência: ilusória e fictícia presença.

Neste ponto o autor discute um dos paradoxos na relação entre cidade/urbano e natureza. Por um lado à urbanização implica em um afastamento da natureza, à medida que passamos a habitar um espaço artificializado, socialmente produzido, que embora ainda possua dinâmicas naturais impactadas pela ação humana, tem seu funcionamento diretamente regulado pela produção social do espaço. Assim a sociedade se distancia da natureza uma vez que ela habita um espaço artificializado em que a natureza sequer é notada. Vive-se em prédios, caminha-se em calçadas de concreto, muitas vezes vive-se uma vida inteira sem avistar um animal selvagem ou sem se colocar o pé na terra. Esse distanciamento, no entanto, conduz a uma busca pela natureza, nem que seja um símbolo, ou um simulacro, algo que lembre a natureza mesmo sem ser de fato.

A urbanização capitalista radicaliza esse distanciamento entre a sociedade e a natureza, uma vez que todo o desenvolvimento tecnológico associado ao infinito processo de acumulação se relaciona com a produção de um espaço urbano intensamente artificializado e tecnificado. Ao mesmo tempo o capitalismo inaugura a produção em 
massa de símbolos que representam a natureza, e que de certa forma fornecem a ilusão de uma reaproximação com a natureza-natural cada vez mais distante. A dispersão urbana intensifica a produção desses símbolos da natureza, ao passo que inclui um elemento novo, que não aparece no texto acima, a produção de uma natureza-artificial no interior mesmo dos empreendimentos imobiliários capitalistas. Então não se trata apenas da produção de símbolos de uma natureza-natural, a muito ausente, mas da produção intencional de uma natureza-artificial que simula a natureza-natural, embora se trate de fato de espaço socialmente produzido. Segundo (Henrique, 2005, p 1):

A cidade, grande realização humana, artefato por excelência e aparente negação da natureza, torna-se o local principal para a observação de uma nova relação, mitológica, capitalista e midiática do homem com a natureza. A natureza, metáfora ou metominia, que já havia sido reificada e incorporada a vida social, ao longo da história do homem, é apropriada e até mesmo produzida, com o objetivo de valorização monetária de objetos, mercadorias, nos mais variados segmentos da produção e dos serviços.

Assim podemos constatar que com a dispersão urbana e o papel central que a produção do espaço passa a ter nos ciclos infindos de acumulação de capital, o aparente paradoxo relacionado à produção da natureza se afirma. Paradoxo, pois um dos significados da palavra natureza remete justamente a ideia de algo não produzido pelo homem, sendo assim a natureza se contraporia a cultura, ou no nosso, caso, ao urbano como espaço socialmente produzido. No entanto, o que temos agora é a produção intencional de uma natureza-artificial como elemento central do processo de produção do espaço, ou pelo menos de uma fração desse processo, ele mesmo definitivamente inserido na lógica de reprodução do capital.

Assim a produção dessa natureza-artificial: bosques, campos, lagos ou até mesmo florestas, se coloca como um elemento central da valorização da terra, dentro do contexto de produção imobiliária financeirizada. Se o discurso de busca de uma aproximação com a natureza e fuga da cidade e seus problemas é um artifício de atração de clientes para os enclaves é importante se ter em conta que a produção de uma natureza-artificial nesses empreendimentos faz parte de uma estratégia de valorização do capital através da produção imobiliária, valorização essa que só é possível através da venda do produto. O que estamos querendo afirmar é que o capital não produz uma natureza-artificial porque se importa com a natureza, mas porque a produção de uma natureza-artificial é um elemento central de viabilização da reprodução do capital a partir da produção imobiliária financeirizada. E essa produção imobiliária se faz comumente a partir da devastação da natureza-natural.

Porém essa natureza-artificial é muito diferente da natureza-natural. Em primeiro lugar a natureza-artificial é uma natureza dócil e desprovida de mistérios. Assim essa natureza contrasta vivamente com a visão medieval de natureza, vista como hostil e ameaçadora, que tem referência em visões contemporâneas que associam as forças da natureza à destruição. A natureza-artificial é produzida como lugar de contemplação, prazer e descanso, assim é uma natureza que importa mais pela sua beleza do que por suas funções ecossistêmicas. Já dissemos anteriormente que justamente por isso, a produção dessa natureza-artificial se dá muito mais por considerações estéticas do que ecológicas. Assim é uma natureza cuja produção se dá totalmente a partir de 
interesses dos seres humanos, tanto dos potenciais consumidores, como das empresas que controlam a produção desses espaços.

Assim a produção dessa natureza-artificial, fortemente associada à dispersão urbana e a produção de enclaves, produzidos como empreendimentos imobiliários dentro da estratégia de reprodução do capital financeiro, se coloca como uma das principais estratégias de diferenciação e venda dos novos produtos imobiliário-financeiros. Assim compreender como se produz essa natureza-artificial, no contexto de dispersão urbana é fundamental para compreender os diferentes contornos do processo de produção do espaço na atualidade.

\section{Conclusão}

A dispersão urbana, como tendência mundial de urbanização capitalista está diretamente associada às novas formas de acumulação do capital que se afirmam a partir da crise do capital na década de 1970. Dentro desse contexto temos uma intensificação dos vínculos entre o capital investido no mercado financeiro e no mercado imobiliário. Uma das consequências da crescente produção imobiliária produzida e diretamente controlada pelo capital imobiliário crescentemente financeirizado é a tendência à dispersão urbana, uma vez que cada empreendimento busca reproduzir dentro de seus limites as condições para sua realização enquanto área urbana, incluso a produção de áreas verdes como uma natureza-artificial que simula a natureza-natural. Estacionamentos, áreas verdes, centros comerciais, escritórios, tentam reproduzir a diversidade do urbano dentro do microcosmo do empreendimento.

Por mais que essa independência do empreendimento em relação à aglomeração não seja totalmente verdadeira o que ocorre é que o capital investido no setor imobiliário busca produzir por si próprio os elementos materiais e imateriais para a valorização de seus empreendimentos. Justamente por isso cada empreendimento pode se localizar, a princípio, em qualquer lugar no tecido urbano ou fora dele, desde que esse lugar seja acessível às redes de transporte e tenha um valor do terreno que viabilize a lucratividade dos empreendimentos. Um dos elementos dessa valorização é justamente a produção de uma natureza-artificial, que simula a natureza-natural, embora não passe de um simulacro, uma versão pasteurizada, uma natureza dócil e destinada a fruição e ao lazer.

De certa forma podemos afirmar que o capital investido imobiliário busca "capitalizar" a preocupação social com o meio ambiente e a revalorização da natureza decorrente do movimento ambientalista. Assim por mais que a preocupação com a natureza no meio urbano não seja algo totalmente novo e mesmo que nem todas as iniciativas de preservação ambiental ou criação de uma natureza-artificial sejam diretamente relacionadas com a dinâmica da produção imobiliária não há como negar que a produção da natureza seja um elemento central da produção imobiliária capitalista na atualidade.

A produção dessa natureza-artificial se dá ao mesmo tempo em que temos, em consequência dessa produção imobiliária, uma intensa devastação da natureza tanto em consequência da produção em si quanto das consequências das mudanças de uso do solo associadas a essa produção. Assim ao mesmo tempo em que a dispersão 
urbana tende a distanciar cada vez mais a sociedade da natureza, no interior dos empreendimentos temos a produção de uma natureza-artificial que parte dessa busca ilusória por uma natureza muitas vezes exterminada pelo próprio empreendimento que se coloca como verde. Assim não é nenhuma incongruência devastar uma área de floresta nativa, para construir um condomínio que tem em sua área de lazer um bosque com plantas exóticas. Nesse sentido, assim como ocorre com o imobiliário, a própria natureza se insere na dinâmica de acumulação do capital como elemento central da valorização do capital investido na produção imobiliária.

\section{Referências bibliográficas}

AGUILAR, A. G. Las mega-ciudades y lãs periferias expandidas : ampliando el concepto en ciudad de Mexico. Revista Eure, ano 28, 85/2002, pp. 121-149.

BLINIKOV, M. et all. Gated communities of the Moscow green belt : newly segregated landscapes and the suburban Russian environment. Geojournal, 66/2006, p 65-81.

CALDEIRA, T. P. R., 2000. Cidade de muros : crime, segregação e cidadania em São Paulo. São Paulo, Editora 34/Edusp.

FIX, M. A. B., 2011. Financeirização e transformações recentes no circuito imobiliário no Brasil. Tese (doutorado) em Economia, Unicamp, Campinas.

HARVEY, D. O enigma do capital e as crises do capitalismo. São Paulo, Boitempo, 2011.

HENRIQUE, W. Florianópolis/Brasil : a felicidade não tem preço, tem endereço : condomínios e loteamentos fechados e apropriação da natureza. Scripta Nova, ano 9, 194/2005.

LEFEBVRE, H., 1999. A revolução urbana. Belo Horizonte, Editora UFMG.

2008. Espaço e política. Belo Horizonte, Editora UFMG.

LENCIONI, S. Concentração e centralização das atividades urbanas : uma perspectiva multiescalar. Revista de Geografia Norte Grande, 39/2008.

MARX, K. Contribuição à crítica da economia política. São Paulo: Martins Fontes, 2003.

OLIVEIRA, C. M. P.; SHIMBO, L. Z., 2011. O "padrão econômico" da habitação: construindo uma trajetória de mercado, Anais do XIV Enampur, Rio de Janeiro.

SALGUEIRO, T. B. Cidade pós-moderna: espaço fragmentado. Revista Território, ano III, 4/1998. 